\title{
Eligibility Criteria Specific to Pancreaticoduodenectomy for Octogenarians: Single-center Opinion
}

\author{
SHUNICHI SHIOZAWA, TAKEBUMI USUI, KOTARO KUHARA, AKIRA TSUCHIYA, TATSUOMI MIYAUCHI, \\ TEPPEI KONO, YUKIO SHIMOJIMA, SHINICHI ASAKA, KENTARO YAMAGUCHI, HAJIME YOKOMIZO, \\ TAKESHI SHIMAKAWA, KAZUHIKO YOSHIMATSU, TAKAO KATSUBE and YOSHIHIKO NARITAKA \\ Department of Surgery, Tokyo Women's Medical University Medical Center East, Tokyo, Japan
}

\begin{abstract}
Background/Aim: Pancreaticoduodenectomy $(P D)$ treatment outcomes in elderly patients have been reported to be acceptable, but the eligibility criteria are not clear. To elucidate the importance of PD in octogenarians in particular, we set five eligibility criteria for elderly patients based on preoperative cardiac and pulmonary function, nutritional status, daily activity status, and psychological independence status for the first time and evaluated prospectively whether the validity of patient selection was adaptable. Patients and Methods: The study population consisted of 222 patients with pancreaticobiliary cancer aged over 70 years. The patients were divided into two groups: 192 patients as septuagenarians and 30 as octogenarians. Postoperative morbidity and long-term outcome were compared between the two groups, and prognostic factors relating to survival time were identified. Results: Octogenarians had a significantly higher frequency of two or more comorbidities $(p<0.0001)$. The difference in the mortality rates between the two groups was not significant, being $3.3 \%$ and $4.2 \%$, respectively. No difference between the two groups was found in overall survival rate, including deaths due to other diseases, for any type of pancreaticobiliary cancer. Independent prognostic factors relating to survival duration were intraoperative blood loss $(p=0.0004)$ and duration of surgery $(p=0.0093)$. Conclusion: These five eligibility criteria for PD in elderly patients are also satisfactorily applicable to octogenarian patients. These criteria may be helpful when uncertainties arise regarding the selection of $P D$.
\end{abstract}

Correspondence to: Shunichi Shiozawa, MD, Ph.D., Department of Surgery, Tokyo Women's Medical University Medical Center East, 2-1-10 Nishiogu, Arakawa-ku, Tokyo, 116-8567, Japan. Tel: +81 338101111, Fax: +81 338945493, e-mail: tansiosu@twmu.ac.jp

Key Words: Pancreaticoduodenectomy, octogenarian, pancreaticobiliary cancer.
The global population of elderly people by 2050 is predicted to be three times that of today, and as the number of elderly people increases, the age of patients with cancer patients also increases. In general, when considering the option of surgery for elderly patients, age alone does not constitute a reason for not performing surgery. If a judgment of eligibility is made on the basis of factors such as the patient's physical competence, the invasiveness of the surgery, and the patient's wishes, even highly invasive surgery can be performed for some elderly patients. However, in the current state of progress of surgical techniques and postoperative management, pancreaticoduodenectomy (PD) is not only invasive, it is also a type of surgery for which the postoperative complications have the potential to be fatal, so rigorous selection of patients is essential (1).

On the other hand, PD is considered a type of surgery in which the surgeon's technical ability markedly affects the outcome, and this is considered to be the reason why there are major differences in outcomes between highvolume centers and other institutions (2-4). On the basis of recent reports of treatment outcomes with PD in elderly patients, it is often considered to be the case that the outcome is acceptable even in comparison with younger age groups. However, this remains a controversial issue (5, $6)$. For example, in the evaluation of treatment outcomes in previous reports, the background fact is that the patient groups consisted of elderly patients who had been rigorously selected, and this does not in fact mean that surgery is indicated for all patients for whom resection is feasible. However, previous reports have not presented the factors indicating PD in elderly patients, and, in particular, have not clearly presented detailed criteria for patient selection.

In this study, in addition to setting PD criteria for elderly patients beforehand and proactively enrolling patients, the validity of patient selection was evaluated on the basis of a surgery risk model. In addition, with the objective of clarifying the significance of PD performance in patients over 80 years old, postoperative morbidity and mortality and long-term 
outcomes were evaluated. Moreover, an attempt was made to identify prognostic factors relating to postoperative survival.

\section{Patients and Methods}

Indication of $P D$ for elderly patients. In this study, it was established beforehand that in order to be eligible for PD, elderly patients had to meet the following five criteria, based on a preoperative assessment of the functioning of various organs: (i) Cardiac function: Ejection fraction, measured by Doppler echocardiography: at least 40. (ii) Pulmonary function: Forced expiratory volume in 1 second (FEV1.0\%), as shown by a spirogram: at least $50 \%$. (iii) Nutritional status: Serum albumin level: at least $3.0 \mathrm{~g} / \mathrm{dl}$. (iv) Daily activity status: Karnofsky performance status: at least $80 \%$. (v) Psychological independence status: Capable of self-determination with respect to surgery.

Treatment. This study included 222 patients for whom PD with lymph node dissection was performed for diseases of the pancreatic head region at Tokyo Women's Medical University Medical Center East between January 2001 and December 2015. The patients were also all over 70 years old and met the above eligibility criteria. In all cases the primary diseases were malignancies, and they included pancreatic head cancer, middle and lower bile duct cancer, and cancer of the ampulla of Vater. In order to clarify the validity of patient selection on the basis of PD outcome in patients over 80 years old, the patients were divided into two groups. The groups consisted of 30 patients over 80 years old (the octogenarian group), and 192 patients from 70 to 79 years old (the septuagenarian group). The comorbidities, operative data, postoperative complications, and overall survival for these two groups were compared. Definitive diagnoses of each of the diseases was achieved by multi-detector row computed tomography and endoscopic retrograde pancreatocholangiography. In the case of patients with severe obstructive jaundice, jaundice reduction was achieved by percutaneous transhepatic biliary drainage, endoscopic nasal biliary drainage, and/or endoscopic retrograde biliary drainage, so that before PD the serum total bilirubin level was no higher than $10 \mathrm{mg} / \mathrm{dl}$. In relation to disease progression, eligibility for PD required preoperative imaging to show the absence of distant metastases and the potential for R0 resection. With pylorus-preserving PD or subtotal stomach-preserving PD as the fundamental type of PD, reconstruction was performed by Child's modified procedure. Conventional PD was only performed if the tumor directly invaded the pyloric region or if perigrastric lymph node metastases were found. The standard range for lymph node dissection was the peripancreatic region (lymph nodes 13 to 17) and the hepatoduodenal ligament (lymph node 12). With respect to lymph nodes around the hepatic artery (lymph node 8) and around the superior mesenteric artery (lymph node 14) and the surrounding nerve plexus, a decision as to whether or not to perform dissection was made on the basis of intraoperative findings, taking preoperative risk evaluation into consideration. As postoperative adjuvant chemotherapy, $1,000 \mathrm{mg} / \mathrm{m}^{2}$ gemcitabine was administered for 6 months, after obtaining informed consent from the patients.

The series of treatments were administered only to patients who had given their written informed consent to do so. This study conformed to the Declaration of Helsinki and was approved by the institutional Ethics Review Board of our hospital (no. 99-1088).

Comorbidities and morbidities. The target patients' comorbidities were defined as follows: Cardiac: hypertension, arrhythmia, coronary artery disease, and a history of myocardial infarction; pulmonary: lung emphysema and chronic bronchitis; hepatic: liver cirrhosis (Child-Pugh score of at least 7); renal: nephrosis and chronic renal failure; metabolic disease: type-2 diabetes and hyperlipidemia; neurogenic: a history of cerebral infarction or hemorrhage. Among the morbidities, surgical complications were evaluated on the basis of the guidelines from the International Study Group on Pancreatic Fistula (7) in the case of postoperative pancreatic fistula and the guideline from the International Study Group of Pancreatic Surgery $(8,9)$ in the case of delayed gastric emptying and post-pancreatectomy hemorrhage. In addition, surgical site infection was judged on the basis of the National Nosocomial Infections Surveillance Guideline (10). Overall complications, including non-surgical morbidities included in the above evaluation items, were placed into five grades on the basis of the Clavien-Dindo guideline (11), with those at grade III or higher considered to be major complications.

Statistical analysis. The individual factors of the patients, that is, the baseline factors, clinical characteristics, operative data and complications, were compared between the two groups of patients using Pearson's chi-squared test and Fisher's exact test. In addition, to identify independent prognostic factors relating to survival, univariate and multivariate analyses were performed using the Cox proportional hazards model for the characteristic medical and surgical risk factors in octogenarians. The observation period was terminated on June 30, 2016, and the overall survival curves, including deaths due to other diseases, were analyzed by the Kaplan-Meier method, with the treatment outcomes for the two groups being compared using the log-rank test. In addition, in order to verify the validity of the indications for PD set in this study, predicted in-hospital mortality rates were calculated and evaluated using the modified estimation of physiological ability and surgical stress (modified E-PASS score) that is in general use as the surgical risk model (12). Taking the significance level in all statistical analyses to be $p<0.05$, statistical analysis was performed using the standard statistical software JMP Pro for Windows (SAS, Cary, NC, USA).

\section{Results}

Patient baselines and clinical characteristics. When comparing all patients' baseline and clinical characteristics between the two groups, females were found to be significantly more numerous among patients in the octogenarian group $(p=0.046)$. In addition, among comorbidities, the American Society of Anesthesiologists score was higher $(p=0.03)$ and the frequencies of hypertension $(p=0.019)$ and pulmonary disease $(p=0.033)$ and the frequency of two or more comorbidities $(p<0.0001)$ were significantly higher in the octogenarian group (Table I).

Surgical outcome. Comparison of the operative data showed differences in surgery types between the two groups, but the area of lymph node dissection was significantly limited for patients in the octogenarian group $(p=0.0005)$. However, there were no differences in blood loss, blood transfusion, duration of surgery, or postoperative stay between the two groups. With respect to morbidity, no differences in surgical 
Table I. Patient characteristics.

\begin{tabular}{|c|c|c|c|}
\hline & $\begin{array}{c}\geq 80 \text { Years } \\
(\mathrm{n}=30) \\
\mathrm{n}(\%)\end{array}$ & $\begin{array}{c}70-79 \text { Years } \\
(\mathrm{n}=192) \\
\mathrm{n}(\%)\end{array}$ & $p$-Value \\
\hline \multicolumn{4}{|l|}{ Patients } \\
\hline Age $(\text { years })^{\mathrm{a}}$ & $82.0(80-88)$ & $76.0(70-79)$ & \\
\hline Gender (M:F) & $11: 19$ & 108:84 & 0.046 \\
\hline \multicolumn{4}{|l|}{ ASA score } \\
\hline $1 / 2$ & $11(36.7)$ & $111(59.8)$ & 0.030 \\
\hline$\geq 3$ & $19(63.3)$ & $81(42.2)$ & \\
\hline Cardiac disease & $23(76.7)$ & $96(50.0)$ & 0.007 \\
\hline Hypertension & $21(70.0)$ & $90(46.9)$ & 0.019 \\
\hline Arrhythmia & $5(20.0)$ & $29(15.1)$ & 0.825 \\
\hline Coronary & $4(13.3)$ & $25(13.0)$ & 0.962 \\
\hline Myocardial infarction & $4(13.3)$ & $21(10.9)$ & 0.700 \\
\hline Pulmonary disease & $7(23.3)$ & $19(15.1)$ & 0.033 \\
\hline Hepatic disease & $1(3.3)$ & $5(2.6)$ & 0.819 \\
\hline Renal disease & $2(6.7)$ & $13(6.8)$ & 0.983 \\
\hline Metabolic disease & $13(43.3)$ & $72(37.5)$ & 0.541 \\
\hline Diabetes & $11(36.7)$ & $54(28.1)$ & 0.339 \\
\hline Hyperlipidemia & $5(16.7)$ & $41(21.4)$ & 0.556 \\
\hline Neurogenic disease & $6(20.0)$ & $27(14.0)$ & 0.395 \\
\hline Comorbidities $(\geq 2)$ & $19(63.3)$ & $38(19.8)$ & $<0.0001$ \\
\hline \multicolumn{4}{|l|}{ Presenting symptoms } \\
\hline Jaundice/biliary drainage & $23(76.7)$ & $169(88.8)$ & 0.091 \\
\hline PTBD & $14(60.9)$ & $137(81.1)$ & 0.899 \\
\hline ERBD. ENBD & $9(39.1)$ & $32(18.9)$ & 0.080 \\
\hline \multicolumn{4}{|l|}{ Laboratory data } \\
\hline Hemoglobin $(<12 \mathrm{~g} / \mathrm{dl})$ & $10(33.3)$ & $42(21.9)$ & 0.168 \\
\hline Albumin $(<3.5 \mathrm{~g} / \mathrm{dl})$ & $7(23.3)$ & $29(15.1)$ & 0.256 \\
\hline CA19-9 $(>37.0 \mathrm{U} / \mathrm{ml})$ & $25(83.3)$ & $151(78.6)$ & 0.556 \\
\hline $\mathrm{CEA}(>5.0 \mathrm{ng} / \mathrm{ml})$ & $11(36.7)$ & $70(36.5)$ & 0.982 \\
\hline \multicolumn{4}{|l|}{ Diagnosis } \\
\hline Pancreatic head cancer & $17(56.7)$ & $106(55.2)$ & 0.131 \\
\hline Biliary duct cancer & $8(26.7)$ & $73(38.0)$ & \\
\hline Ampullary cancer & $5(16.6)$ & $13(6.8)$ & \\
\hline
\end{tabular}

M:F: Male:female, ASA: American Society of Anesthesiologists, PTBD percutaneous transhepatic biliary drainage, ENBD: endoscopic nasal biliary drainage, ERBD: endoscopic retrograde biliary drainage, CA199: Carbohydrate antigen 19-9, CEA: Carcinoembryonic antigen. ${ }^{\text {aValues }}$ are median (range).

complications were found, but among non-surgical complications, the frequency of delirium was significantly higher in the octogenarian group $(p=0.026)$.

Evaluation of overall complications showed no significant difference in major complications at grade III or higher according to the Clavien-Dindo guidelines, with four patients $(13.3 \%)$ in the octogenarian group, and 19 patients $(9.9 \%)$ in the septuagenarian group $(p=0.625)$. In addition, no differences in-hospital mortality rates were found, these being $3.3 \%(n=1)$ in the octogenarian group and $4.2 \%(n=7)$ in the septuagenarian groups, respectively (Table II).

Long-term outcome in all patients and in subgroups. Figure 1A shows the overall survival curve for the two groups, including
Table II. Operative data and complications

\begin{tabular}{|c|c|c|c|}
\hline & $\begin{array}{c}\geq 80 \text { Years } \\
(n=30) \\
\mathrm{n}(\%)\end{array}$ & $\begin{array}{c}70-79 \text { Years } \\
(n=192) \\
\mathrm{n}(\%)\end{array}$ & $p$-Value \\
\hline \multicolumn{4}{|l|}{ Procedure } \\
\hline PD & $4(13.3)$ & $29(15.1)$ & 0.967 \\
\hline PPPD & $11(36.7)$ & $68(35.4)$ & \\
\hline SSPPD & $15(50.0)$ & $95(49.5)$ & \\
\hline Lymph node dissection & $17(56.7)$ & $161(83.9)$ & 0.001 \\
\hline SMV/PV resection & $2(6.7)$ & $21(10.9)$ & 0.475 \\
\hline Blood loss $(\mathrm{g})^{\mathrm{a}}$ & $528(296-1040)$ & $645(262-1826)$ & 0.655 \\
\hline Blood transfusion & $12(40.0)$ & $65(33.9)$ & 0.511 \\
\hline Duration of surgery $(\mathrm{min})^{\mathrm{a}}$ & $378(251-526)$ & $435(284-690)$ & 0.766 \\
\hline Postoerative hospital staya & $32(19-42)$ & $30(17-63)$ & 0.611 \\
\hline Morbidity & $13(43.3)$ & $68(35.4)$ & 0.402 \\
\hline \multicolumn{4}{|l|}{ Surgical complications } \\
\hline POPF (grade B/C) & $2(6.7)$ & $25(13.0)$ & 0.322 \\
\hline Biliary leakage & $1(3.3)$ & $5(2.6)$ & 0.819 \\
\hline Delayed gastric emptying & $1(3.3)$ & $4(2.1)$ & 0.668 \\
\hline Postoperative bleeding & 00 & $2(1.0)$ & 0.574 \\
\hline Intraabdominal abscess & $1(3.3)$ & $6(3.1)$ & 0.952 \\
\hline Surgical site infection & $2(6.7)$ & $11(5.7)$ & 0.839 \\
\hline Reoperation & 00 & $3(1.7)$ & 0.491 \\
\hline \multicolumn{4}{|l|}{ Non-surgical complications } \\
\hline Pneumonia & $4(13.3)$ & $10(5.2)$ & 0.089 \\
\hline Aspiration & $2(6.7)$ & $6(3.1)$ & \\
\hline Delirium & $13(43.3)$ & $46(23.9)$ & 0.026 \\
\hline \multicolumn{4}{|l|}{ Overall } \\
\hline None/Mild (Grade I-II) & $26(86.7)$ & $173(90.1)$ & 0.625 \\
\hline Moderate (Grade IIIa) & $2(6.7)$ & $12(6.3)$ & \\
\hline Severe (Grade IIIb-IV) & $2(6.7)$ & $7(3.6)$ & \\
\hline Mortality (30 day/in-hospital) & $1(3.3)$ & $7(4.2)$ & 0.932 \\
\hline
\end{tabular}

PD: Pancreaticoduodenostomy, PPPD: pylorus-preserving pancreaticoduodenectomy, SSPPD: subtotal stomach-preserving pancreaticoduodenectomy, SMV: supramesenteric artery, PV: portal vein, POPF: post operative pancreatic fistula formation (International Study Group on Pancreatic Fistula, grade $\mathrm{B}+\mathrm{C}$ ). Overall morbidity is shown as Clavien-Dindo classification. ${ }^{a}$ Values are median (range).

deaths due to other diseases. In the octogenarian group, the survival rates at 1, 3 and 5 years after surgery were $94 \%, 30 \%$, and $17 \%$, respectively, and those in the septuagenarian group were $91 \%, 42 \%$, and $32 \%$, there being no significant difference between the groups $(p=0.1972)$. The result of subgroup analysis of overall survival by primary disease was that the rate of pancreatic cancer was lower somewhat in the octogenarian group ( $p=0.0655$; Figure 1B), but no significant differences in bile duct cancer ( $p=0.8479$; Figure 1C) or ampullary cancer $(p=0.3817)$ were found between the two groups (Figure 1D).

Independent post-PD risk factors for octogenarian patients. In the octogenarian group, Cox proportional hazards model analysis was performed with 19 clinicopathological variables, consisting of seven medical risk factors, 11 surgical risk factors, and performance versus non-performance of adjuvant 


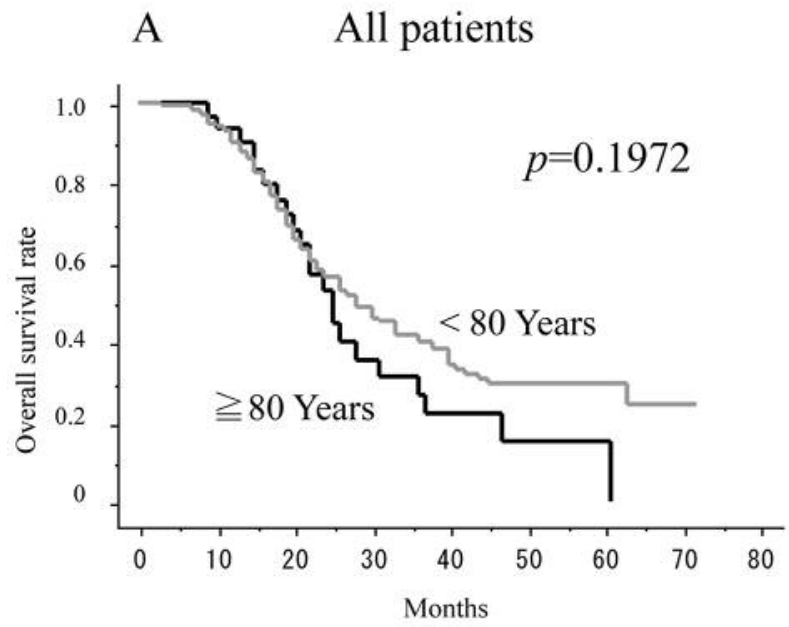

C Bile duct cancer

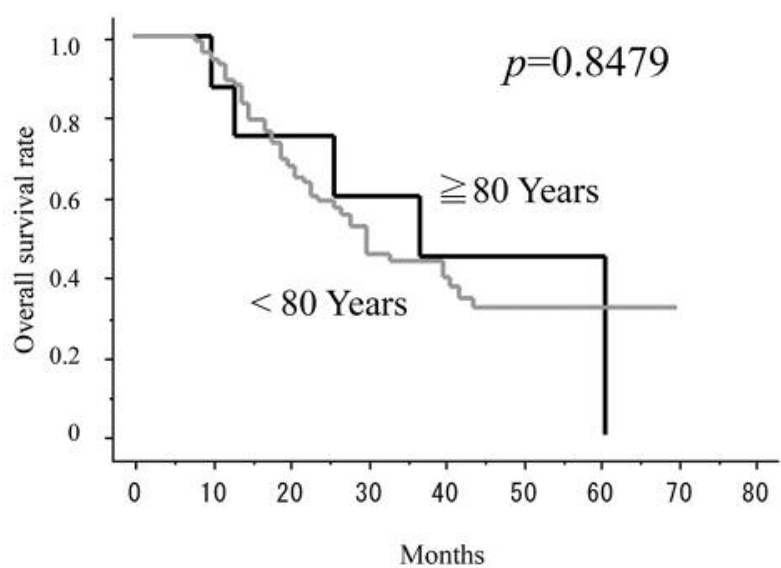

B Pancreatic cancer

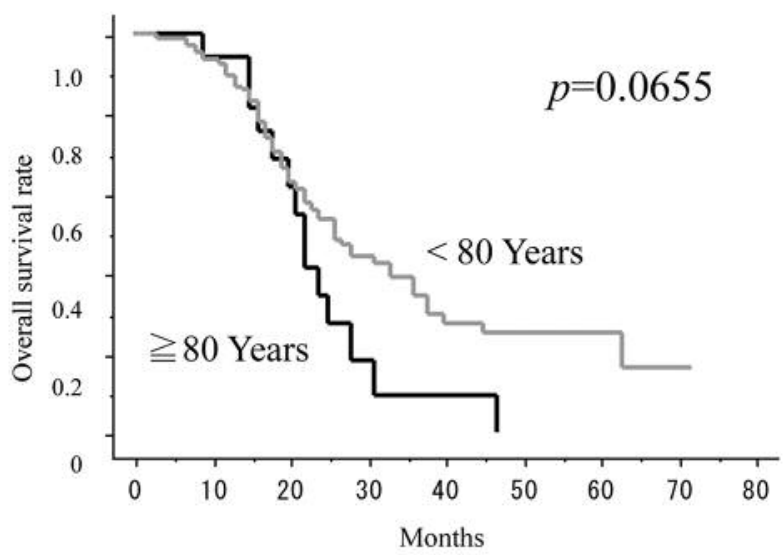

D Ampullary cancer

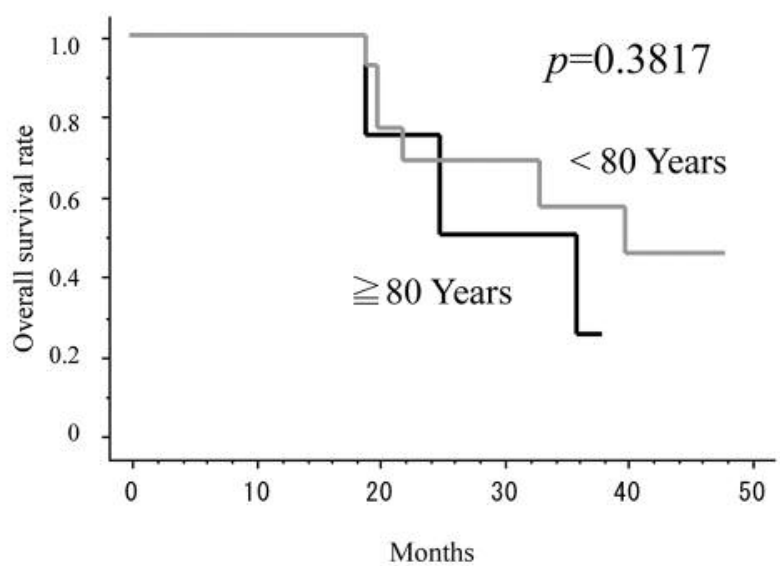

Figure 1. Cumulative overall survival curves after pancreaticoduodenectomy (PD) for pancreaticobiliary cancers comparing all patients in the octogenarian group $(n=30)$ to those in the septuagenarian group $(n=192)(A)$, and comparing those undergoing PD for pancreatic cancer ( $n=17$ and $n=106$, respectively) $(B)$, for bile duct cancer ( $n=8$ and $n=73$, respectively) $(C)$, and for ampullary cancer ( $n=5$ and $n=13$, respectively) $(D)$.

chemotherapy. Univariate analysis showed significant effects on survival time due to diagnosis of pancreatic cancer $(p=0.0424)$, intraoperative blood loss $(p=0.0064)$, red blood cell transfusion $(p=0.0329)$, and duration of surgery $(p=0.001)$. Multivariate analysis showed blood loss [odds ratio $(\mathrm{OR})=6.2 ; 95 \%$ confidence interval $(\mathrm{CI})=3.163-35.822 ; p=0.0004]$ and duration of surgery $(\mathrm{OR}=3.6 ; 95 \% \mathrm{CI}=1.488-23.669 ; p=0.0093)$ to be independent poor prognostic factors (Table III).

Suitability of PD for elderly patients. Receiver operator characteristic curve analysis by modified E-PASS, which is a surgical risk model, was performed, with in-hospital mortality in all patients as the outcome. The area under the curve was high at 0.83 (95\% $\mathrm{CI}=2.34$ to $10.65 ; p=0.0021)$, the modified
E-PASS was found to have moderate accuracy. The median values of predicted in-hospital mortality rates calculated from the modified E-PASS were $9.4 \%$ and $12.3 \%$ in the septuagenarian and in the octogenarian groups, respectively.

\section{Discussion}

Surgery for pancreaticobiliary cancers, which have poor prognoses, in elderly patients who have short mean life expectancies remains controversial, and the optimal evidencebased treatment has not been clarified $(1,2)$. This is because elderly people, especially those over 80 years old, have short life expectancies independently of their cancer, and individual differences in physical and psychological competence are also 
Table III. Cox proportional hazard regression analysis for overall survival.

\begin{tabular}{|c|c|c|c|c|c|}
\hline \multirow[t]{2}{*}{ Variables } & & \multirow[t]{2}{*}{$\mathrm{N}$} & \multirow{2}{*}{$\begin{array}{c}\text { Univariate } \\
p \text {-Value }\end{array}$} & \multicolumn{2}{|c|}{ Multivariate } \\
\hline & & & & $\mathrm{HR}(95 \% \mathrm{CI})$ & $p$-Value \\
\hline \multicolumn{6}{|l|}{ Medical risk factors } \\
\hline \multirow[t]{2}{*}{ Gender } & Male & 11 & 0.9551 & & \\
\hline & Female & 19 & & & \\
\hline \multirow[t]{2}{*}{ ASA score } & $1 / 2$ & 11 & 0.8667 & & \\
\hline & $\geq 3$ & 19 & & & \\
\hline \multirow[t]{2}{*}{ Comorbidities $(\geq 2)$} & Positive & 19 & 0.0672 & & \\
\hline & Negative & 11 & & & \\
\hline \multirow[t]{2}{*}{ Jaundice/biliary drainage } & Positive & 23 & 0.6627 & & \\
\hline & Negative & 7 & & & \\
\hline \multirow[t]{2}{*}{ Hemoglobine level } & $<12(\mathrm{~g} / \mathrm{dl})$ & 10 & 0.4807 & & \\
\hline & $\geq 12$ & 20 & & & \\
\hline \multirow[t]{2}{*}{ Albumin level } & $<3.5(\mathrm{~g} / \mathrm{dl})$ & 7 & 0.5876 & & \\
\hline & $\geq 3.5$ & 23 & & & \\
\hline \multirow[t]{2}{*}{ Diagnosis } & Pancreatic cancer & 17 & 0.0424 & & \\
\hline & Other & 13 & & & \\
\hline \multicolumn{6}{|l|}{ Surgical risk factors } \\
\hline \multirow[t]{3}{*}{ Procedure } & $\mathrm{PD}$ & 4 & 0.5321 & & \\
\hline & PPPD & 11 & & & \\
\hline & SSPPD & 15 & & & \\
\hline \multirow[t]{2}{*}{ Pancreas texture } & Soft & 12 & 0.2481 & & \\
\hline & Hard & 18 & & & \\
\hline \multirow[t]{2}{*}{ Wirsung duct size } & $<3(\mathrm{~mm})$ & 10 & 0.1674 & & \\
\hline & $\geq 3$ & 20 & & & \\
\hline \multirow{2}{*}{$\mathrm{PV} / \mathrm{SMV}$ resection } & Positive & 2 & 0.8122 & & \\
\hline & Negative & 28 & & & \\
\hline \multirow[t]{2}{*}{ Blood loss } & $<500(\mathrm{~g})$ & 11 & 0.0064 & $6.2(3.163-35.822)$ & 0.0004 \\
\hline & $\geq 500$ & 19 & & & \\
\hline \multirow[t]{2}{*}{ Red blood cell transfusion } & Positive & 12 & 0.0329 & & \\
\hline & Negative & 18 & & & \\
\hline \multirow[t]{2}{*}{ Duration of surgery } & $<6 \mathrm{~h}$ & 11 & 0.001 & $3.6(1.488-23.669)$ & 0.0093 \\
\hline & $\geq 6 \mathrm{~h}$ & 19 & & & \\
\hline \multirow[t]{2}{*}{ POPF grade } & A & 28 & 0.4057 & & \\
\hline & $\mathrm{B} / \mathrm{C}$ & 2 & & & \\
\hline \multirow[t]{2}{*}{ Overall morbiditiy } & Grade I-II & 26 & 0.4716 & & \\
\hline & Grade IIIa-V & 4 & & & \\
\hline \multirow[t]{2}{*}{ Lymph node status } & No & 8 & 0.2069 & & \\
\hline & N1 & 22 & & & \\
\hline \multirow[t]{2}{*}{ Resection margin } & $\mathrm{R} 0$ & 29 & 0.5014 & & \\
\hline & $\mathrm{R} 1$ & 1 & & & \\
\hline \multirow[t]{2}{*}{ Adjuvant chemotherapy } & Yes & 21 & 0.8412 & & \\
\hline & No & 9 & & & \\
\hline
\end{tabular}

greater than in younger age groups. In the present study, PD eligibility criteria specific to elderly patients were set for the first time, decisions were made about the suitability of PD, and the treatment outcomes were analyzed. It was found that although patients in the octogenarian group had the disadvantage of having a significantly higher number of comorbidities present before surgery, if they met the eligibility criteria, they showed no significant differences from the septuagenarian group with respect to postoperative hospital stay, morbidity, or mortality. In addition, the required result was achieved with respect to pancreatic head cancer, middle and lower bile duct cancer, and cancer of the ampulla of Vater, in that there were no significant differences between the two groups in overall survival, including death due to other diseases. On these grounds, the evaluation result was that the five eligibility criteria set for this study are valid as conditions 
required for PD including octogenarians, and can therefore be applied at other medical institutions. On the other hand, in a multivariate analysis of factors relating to prognosis, two factors, namely blood loss and duration of surgery, were independent poor prognostic factors. This clearly shows that intraoperative factors other than the eligibility criteria had major effects on prognosis in patients in the octogenarian group.

In recent years, on the basis of meta-analyses relating to the appropriateness or otherwise of PD for elderly patients, there have been reports stating that if elderly patients are selected appropriately, the treatment outcomes are no worse than with younger age groups (13). However, there have been no reports of prospective studies that clearly stated the selection criteria and triage methods used. As background issues, it is probable that surgical techniques based on the surgeon's long-term experience and progress in perioperative management for avoidance of aspiration pneumonia, delirium, and other morbidities characteristic of elderly patients have major effects on treatment outcome $(14,15)$. But, it is difficult to evaluate the effects of these objectively. In particular, it is not uncommon for elderly patients to have comorbidities such as hypertension, chronic heart disease, diabetes, and a history of cerebral infarction as multiple complications, and preoperative functional evaluation of essential organs is considered to be important for the selection of patients for surgery. Surgical risk evaluation methods such as the physiologicaI and operative severity score for enumeration of mortality and morbidity (POSSUM score) (16), modified E-PASS score (12), and comprehensive geriatric assessment (CGA) (17) are already in wide use, but judgments on the basis of these evaluation methods also have major impacts on patient's own decision as to whether they wish to undergo surgery or not.

In this study, eligibility criteria specific to PD for elderly patients were set. As a result of a re-evaluation of prospectively accumulated data by modified E-PASS score, the median predicted in-hospital mortality rates were calculated to be $9.4 \%$ and $12.3 \%$ in septuagenarians and octogenarians, respectively. Regarding the surgical factors among these, in some patients in the octogenarian group, surgery that intentionally moderated dissection of lymph nodes and nerve plexuses around the hepatic artery (lymph node 8 ) and around the superior mesenteric artery (lymph node 14) was performed (18). This is considered to be one reason why favorable results in terms of reduction of duration of surgery, hemorrhage reduction, and maintenance of postoperative quality of life were achieved. These results showed that the actual in-hospital mortality rates were lower than the predicted rates, and that the eligibility criteria for PD in elderly patients were largely appropriate. In addition, blood loss and duration of surgery, which are important evaluation factors for modified E-PASS score, were shown by the analysis in the present study to be independent prognostic factors. This finding supports the accuracy of modified E-PASS score.

Several limitations of this study should be acknowledged. Firstly, taking into consideration the high invasiveness of the surgery itself, the five eligibility criteria set in this study were based on the functions of each essential organ having sufficient safety margins. It is therefore possible that the applicability of PD to elderly patients could be expanded on the basis of more challenging criteria. Secondly, the results of this study were based on analyses with a small number of patients at a single center, and it is therefore hoped that future analyses of functional evaluation parameters for elderly patients will be performed under the same conditions at multiple institutions. It is further hoped that a comparison of perioperative complications and long-term outcomes on the basis of such results will enable preparation of guidelines for the accurate selection of low-risk elderly patients appropriate to the level of surgical invasiveness. Thirdly, it goes without saying that perioperative PD management is as important as eligibility for surgery itself. No approach to objective evaluation of the factors relating to perioperative management were proposed in this study, and this is therefore an important area for future research.

In conclusion, simple prolongation of biological life is not the sole objective of PD for elderly patients, and decisions must be made from the point of view of prolonging healthy life. In other words, in addition to the aim of radical treatment by surgery, the hope is for surgery that does not reduce the patent's postoperative quality of life. In this context, the PD eligibility criteria for elderly patients set in this study may be helpful when uncertainties arise regarding the selection of PD.

\section{Conflicts of Interest}

The Authors have no conflicts to disclose in regard to this clinical study.

\section{Funding}

The Authors received no specific funding to complete this work.

\section{References}

1 Adham M, Bredt LC, Robert M, Perinel J, Lombard-Bohas C, Ponchon $\mathrm{T}$ and Valette PJ: Pancreatic resection in elderly patients: Should it be denied? Langenbecks Arch Surg 399(4): 449-459, 2014.

2 obert AM, Nita A and David CC: What constitutes a "highvolume" hospital for pancreatic resection? J Am Coll Surg 206: 622-628, 2008.

3 Schmidt CM, Turrini O, Parikh P, House MG, Zyromski NJ, Nakeeb A, Howard TJ, Pitt HA and Lillemoe KD: Effect of hospital volume, surgeon experience, and surgeon volume on patient outcomes after pancreaticoduodenectomy. Arch Surg 145(7): 634-640, 2010. 
4 Schneider EB, Ejaz A, Spolverato G, Hirose K, Makary MA, Wolfgang CL, Ahuja N, Weiss M and Pawlik TM: Hospital volume and patient outcomes in hepato-pancreato-biliary surgery: Is assessing differences in mortality enough? J Gastrointest Surg 18: 2105-2115, 2014.

5 Faraj W, Alameddine R, Mukherji D, Musallam K, Haydar A, Eloubiedi M, Shamseddine A and Khalife M: Postoperative outcomes following pancreaticoduodenectomy: How should age affect clinical practice? World J Surg Oncol 11: 131, 2013.

6 Gerstenhaber F, Grossman J, Lubezky N, Itzkowitz E, Nachmany IS, Ben-Haim M, Nakache R, Klausner JM and Lahat G: Pancreaticoduodenectomy in elderly adults: Is it justified in terms of mortality, long-term morbidity, and quality of life? J Am Geriatr Soc 61: 1351-1357, 2013.

7 Bassi C, Dervenis C, Butturini G, Fingerhut A, Yeo C, Izbicki J, Neoptolemos J, Sarr M, Traverso W and Buchler M; International Study Group on Pancreatic Fistula Definition: Postoperative pancreatic fistula: An International Study Group (ISGPF) definition. Surgery 138(1): 8-13, 2005.

8 Wente MN1, Bassi C, Dervenis C, Fingerhut A, Gouma DJ, Izbicki JR, Neoptolemos JP, Padbury RT, Sarr MG, Traverso LW, Yeo CJ and Büchler MW: Delayed gastric emptying (DGE) after pancreatic surgery: a suggested definition by the International Study Group of Pancreatic Surgery (ISGPS). Surgery 142(5): 761-768, 2007.

9 Wente MN, Veit JA, Bassi C, Dervenis C, Fingerhut A, Gouma DJ, Izbicki JR, Neoptolemos JP, Padbury RT, Sarr MG, Yeo CJ and Büchler MW: Postpancreatectomy hemorrhage (PPH): an International Study Group of Pancreatic Surgery (ISGPS) definition. Surgery 142(1): 20-25, 2007.

10 Mangram AJ, Horan TC, Pearson ML, Silver LC and Jarvis WR: Guideline for Prevention of Surgical Site Infection, 1999. Centers for Disease Control and Prevention (CDC) Hospital Infection Control Practices Advisory Committee. Am J Infect Control 27(2): 97-132, 1999.

11 Dindo D, Demartines $\mathrm{N}$ and Clavien PA: Classification of surgical complications: A new proposal with evaluation in a cohort of 6336 patients and results of a survey. Ann Surg 240(2): 205-213, 2004
12 Haga Y, Ikejiri K, Wada Y, Takahashi T, Ikenaga M, Akiyama N, Koike S, Koseki M and Saitoh T: A multicenter prospective study of surgical audit systems. Ann Surg 253(1): 194-201, 2011.

13 Casadei R, Ricci C, Lazzarini E, Taffurelli G, D'Ambra M, Mastroroberto M, Morselli-Labate AM and Minni F: Pancreatic resection in patients 80 years or older: a meta-analysis and systematic review. Pancreas 43(8): 1208-1218, 2014.

14 Leung JM, Sands LP, Paul S, Joseph T, Kinjo S and Tsai T: Does postoperative delirium limit the use of patient-controlled analgesia in older surgical patients? Anesthesiology 111(3): 625631, 2009.

15 Shirai Y, Shiba H, Horiuchi T, Saito N, Furukawa K, Sakamoto T, Gocho T, Ishida Y and Yanaga K: Assessment of outcome after pancreaticoduodenectomy by junior surgeons. Anticancer Res 36(7): 3505-3510, 2016.

16 Copeland GP, Jones D and Walters M: POSSUM: a scoring system for surgical audit. Br J Surg 78: 356-360, 1991.

17 Decoster L, Van Puyvelde K, Mohile S, Wedding U, Basso U, Colloca G, Rostoft S, Overcash J, Wildiers H, Steer C, Kimmick G, Kanesvaran R, Luciani A, Terret C, Hurria A, Kenis C, Audisio $\mathrm{R}$ and Extermann $\mathrm{M}$ : Screening tools for multidimensional health problems warranting a geriatric assessment in older cancer patients: an update on SIOG recommendations. Ann Oncol 26(2): 288-300, 2015.

18 Jang JY, Kang MJ, Heo JS, Choi SH, Choi DW, Park SJ, Han SS, Yoon DS, Yu HC, Kang KJ, Kim SG and Kim SW: A prospective randomized controlled study comparing outcomes of standard resection and extended resection, including dissection of the nerve plexus and various lymph nodes, in patients with pancreatic head cancer. Ann Surg 259(4): 656-664, 2014.

Received February 20, 2017

Revised March 16, 2017

Accepted March 20, 2017 